Research Article

\title{
A Continuous-Time Version of a Delegated Asset Management Problem
}

\author{
Yanan $\mathrm{Li}^{1}{ }^{1} \mathrm{Zengti}_{\mathrm{Li}}{ }^{2}$ and Chuanzheng $\mathrm{Li} \mathbb{D}^{1}$ \\ ${ }^{1}$ School of Finance, Capital University of Economics and Business, Beijing 100070, China \\ ${ }^{2}$ School of Science, Langfang Normal University, Langfang 065000, China \\ Correspondence should be addressed to Chuanzheng Li; 13931239029@163.com
}

Received 31 March 2020; Accepted 27 September 2020; Published 30 November 2020

Academic Editor: Wenguang Yu

Copyright (c) 2020 Yanan Li et al. This is an open access article distributed under the Creative Commons Attribution License, which permits unrestricted use, distribution, and reproduction in any medium, provided the original work is properly cited.

This paper develops a continuous-time model to study the widely used investment mandates in the institutional asset management industry. In this paper, just like He and Xiong (2013), we suppose that the asset management industry has a two-layered incentive structure, and fund families charging investors fixed management fees while compensating individual fund managers based on fund performance. Different from He and Xiong (2013), we suppose that the fund family aims to select an optimal incentive strategy to maximize its terminal benefits, while the fund manager needs to select the optimal effort level and the optimal investment portfolio to maximize his terminal net discounted compensation in a continuous-time model. By using dynamic programming principle and stochastic differential game theory, the optimal strategies and value functions of both sides are derived. At last, numerical studies are provided to illustrate the effects of all the parameters on the optimal strategies. The result reveals that the optimal incentive mechanism will redistribute both the benefit of the fund families and the cost of the fund managers' effort.

\section{Introduction}

Since professional cooperation plays an important role in making a successful investment, most investors handover their money to security companies, fund companies, or other financial management institutions, and the study of the asset management problem has attracted more and more attention. See [1-5] to name just a few.

In the internal of fund management companies, investment decisions are usually made by the fund manager, and the performance of investment portfolio is closely related to the investment strategy and the fund manager's effort level. So, the principal-agent relationship which affects the investment strategy inevitably exists in the investment process, and it is necessary to consider the investment problem under the principal-agent system.

For agency problems, most of the early literature focuses on discrete time models (for instance, [6-8] or [9] for a book treatment). A continuous-time model is first studied by [10], and it shows that the optimal contract is linear. Then, the work is extended by [11-14]. Nowadays, this kind of problem is usually solved by the stochastic maximum principle or martingale representation theorem. For the former, we can refer to [15-17]; for the latter, we can refer to $[18,19]$.

Different from the aforementioned models, [20] allows the manager to face investment opportunities in two markets instead of one and develops a discrete time model to study the widely used investment mandates in the institutional asset management industry. In this paper, we establish a continuous-time model based on [20] and find the optimal strategies of both the fund family and the fund manager. There are some differences between our model and the model mentioned in [20]:

(1) The effort level takes its value in an interval in this paper while the effort level is zero or a fixed value in [20]

(2) The returns from the two markets are stochastic processes in this paper while the single period model is considered in [20] 
(3) Incentive compatibility constraint which must be satisfied in [20] is not necessary in this paper

Since the model in our paper is different from that in [20] and the method used in [20] does not work anymore, we use the stochastic differential game theory to get the optimal strategies of both the fund family and the fund manager. This tool can also be used for other investment problems under principle agency systems.

This paper is organized as follows. In Section 2, a mathematical formulation of the investment problem in the principle agency system is formulated. In Section 3, the problem with no agency conflicts is considered, and the optimal effort level is derived. Some numerical results are presented in this section to illustrate some comparative statics results. In Section 4, the problem with agency conflicts is considered, and the optimal policies of both the fund family and the fund manager are presented. Numerical analysis is also mentioned in this section to get the effects of all parameters on the optimal strategy. A conclusion is made in Section 5 which includes a comparison of the optimal effort levels with and without agency conflicts.

\section{Problem Formulation}

This paper embeds the optimal problem into the framework adopted in [20]. Suppose that the fund manager has superior expertise in primary market 1 , that is, the effort of the fund manager can affect the gains of market 1 . At the same time, he can pursue outside investment opportunity in market 2. The fund family aims to select an optimal incentive strategy to maximize its terminal gains, while the fund manager needs to select the optimal effort level and the optimal investment portfolio to maximize his terminal net discounted compensation. In the following, we will establish the mathematical model of the problem on the probability space $(\Omega, \mathscr{F}, P)$.

Referring to [18], we suppose that the manager's effort level $n$ cannot be observed by the fund family and has a positive effect on the gain of market 1 . Derived from [18] and considering a more concrete model, let us assume that $R_{1}^{n}(t)$, the gain of market 1 under the fund manager's effort level $n$, satisfies

$$
\mathrm{d} R_{1}^{n}(t)=R_{1}^{n}(t)\left[\left(r+\mu_{1}+n\right) \mathrm{d} t+\sigma_{1} \mathrm{~d} W^{1}(t)\right],
$$

where $r$ represents the risk-free rate, $\mu_{1}>0$ is a constant, and $W^{1}(t)$ is a standard Brown motion on $(\Omega, \mathscr{F}, P)$. Clearly, the more the manager's efforts, the bigger the drift coefficient of market 1. Suppose that the return of market 2 satisfies

$$
\mathrm{d} R_{2}(t)=R_{2}(t)\left[\left(r+\mu_{2}\right) \mathrm{d} t+\sigma_{2} \mathrm{~d} W^{2}(t)\right],
$$

where $\mu_{2}>0$ is a constant, and $W^{2}(t)$ is a standard Brown motion on $(\Omega, \mathscr{F}, P)$. Denote the correlation coefficient of $W^{1}(t)$ and $W^{2}(t)$ by $\rho$.

The manager will decide his effort level in the beginning and get a compensation from the fund family at the terminal time $T$. Suppose that the compensation is a function of the terminal benefit of the investment portfolio and denote it by $w(\cdot)$. Clearly, the fund family aims to find the optimal incentive strategy to control the performance of the fund and maximize its terminal net value. At the same time, the fund manager needs to look for the optimal effort level and the optimal investment portfolio to maximize his terminal net discounted compensation (wage or dividend). This is a noncooperative game. We are particularly interested in analyzing the joint implications of these two dimensions.

According to [15], we know that the fund family is in the leading position, and the manager should determine the effort level and the investment strategy according to the fund families' incentive strategy. Therefore, first, we intend to fix the compensation strategy $w(\cdot)$ and get the manager's optimal investment strategy and effort level which are expressed with the help of $w(\cdot)$. Then, we put the manager's optimal strategy into the fund family's optimization problem and get the optimal $w(\cdot)$.

The above analysis tells us that, first, we need to fix the incentive strategy $w(\cdot)$ and consider the manager's optimization problem. Consider the manager's policy $\pi=\left(b_{1, t}^{\pi}, b_{2, t}^{\pi}, n^{\pi}\right)$, where $b_{i, t}^{\pi}, i=1,2$ represent the capital invested in market $i$ and $n^{\pi}$ captures the effort level. Since the manager can invest in market 1 , market 2, or risk-free market, by some simple calculations, we can have that the return of the investment portfolio under this policy satisfies

$$
\mathrm{d} X^{\pi}(t)=\left(X^{\pi}(t) r+b_{1, t}^{\pi}\left(\mu_{1}+n^{\pi}\right)+b_{2, t}^{\pi} \mu_{2}\right) \mathrm{d} t+\sigma^{\pi}(t) \mathrm{d} W(t),
$$

where $\sigma^{\pi}(t)=\sqrt{b_{1, t}^{\pi 2} \sigma_{1}^{2}+b_{2, t}^{\pi 2} \sigma_{2}^{2}+2 \rho b_{1, t}^{\pi} b_{2, t}^{\pi} \sigma_{1} \sigma_{2}}$, and $W(t)$ is the Brown motion on $(\Omega, \mathscr{F}, P)$.

Let $\left\{\mathscr{F}_{t}^{W}\right\}_{t \geq 0}$ be the natural filtration generated by $W(t)$. Now, let us give the definition of the manager's admissible control. A control policy $\pi=\left(b_{1, t}^{\pi}, b_{2, t}^{\pi}, n^{\pi}\right)$ is said to be admissible if $b_{i, t}^{\pi}, i=1,2$ are $\mathscr{F}_{t}^{W}$ predictable processes and $n^{\pi} \geq 0$. We denote the set of all admissible controls by $\Pi$. Then, we can establish a mathematical model of the manager's optimization problem.

The manager's objective is finding the optimal effort level and investment policy to maximize his utility of compensation minus his effort cost. That is, the objective of the manager is to maximize

$$
J_{m}^{\pi}(t, x ; w)=E\left[U_{m}\left(w\left(X^{\pi}(T)\right)\right)-C\left(n^{\pi}\right) \mid X^{\pi}(t)=x\right],
$$

over $\pi \in \Pi$. Here, $U_{m}(\cdot)$ is the manager's utility function, and $C(n)$ is the manager's effort cost under the effort level $n$. Following the structure imposed in [19], we have

$$
C(n)=\int_{0}^{T} e^{r(T-t)} \frac{\theta n^{2}}{2} R_{1}^{n}(t) \mathrm{d} t,
$$

where $\theta>0$ is the cost parameter of the effort level.

Denote the optimal strategy by $\pi^{w *}$, and record the value function as

$$
V_{m}(t, x ; w)=\sup _{\pi \in \Pi} J_{m}^{\pi}(t, x ; w)=J_{m}^{\pi^{* w}}(t, x ; w) .
$$

Next, let us consider the fund families' optimization problem. An incentive policy $w(\cdot)$ is said to be admissible if 
$w(\cdot)$ is a continuous increasing function. We denote the set of all admissible controls by $\widehat{\Pi}$. The objective of the fund family is to find the optimal incentive policy to maximize its net benefit. Suppose it is risk neutral, then the objective of the fund family is to maximize

$$
J_{f}^{w}(t, x)=E\left[X^{\pi^{w *}}(T)-w\left(X^{\pi^{w *}}(T)\right) \mid X^{\pi^{w *}}(t)=x\right],
$$

over $w(\cdot) \in \widehat{\Pi}$. Denote the value function by

$$
V_{f}(t, x)=\sup _{w \in \widehat{\Pi}} J_{f}^{w}(t, x) .
$$

\section{The Problem with No Agency Conflicts}

Let us consider the case when there are no agency conflicts in this section. That is, the fund manager can get all the benefits from asset management. The result in this section is meaningful since it can be used to solve the manager's optimization problem with agency conflicts.

3.1. Preliminary Result with the Effort Level Fixed. First, let us analyze the optimal investment problem of the manager with the effort level $n$ fixed. Let

$$
J^{\pi}(t, x ; n)=E\left[U_{m}\left(X^{\pi}(T ; n)\right) \mid X^{\pi}(t ; n)=x\right],
$$

where $X^{\pi}(t ; n)$ is the process defined in (3) with the effort level $n$ and investment policy $\left(b_{1, t}^{\pi}, b_{2, t}^{\pi}\right)$.

Define

$$
V(t, x ; n)=\sup _{\pi \in \Pi} J^{\pi}(t, x ; n) .
$$

According to [21], we know that $V(t, x ; n)$ satisfies the HJB equation (Hamilton-Jacobi-Bellman equation):

$$
\begin{aligned}
-V_{t}(t, x ; n) & =\sup _{\pi \in \Pi}\left\{\left[r x+b_{1, t}^{\pi}\left(\mu_{1}+n\right)+b_{2, t}^{\pi} \mu_{2}\right] V_{x}(t, x ; n)+\frac{\sigma^{\pi 2}}{2} V_{x x}(t, x ; n)\right\}, \\
V(T, x ; n) & =U_{m}(x)
\end{aligned}
$$

where $\sigma^{\pi}=\sqrt{\left(b_{1, t}^{\pi}\right)^{2} \sigma_{1}^{2}+\left(b_{2, t}^{\pi}\right)^{2} \sigma_{2}^{2}+2 \rho b_{1, t}^{\pi} \sigma_{1} b_{2, t}^{\pi} \sigma_{2}}$. Without losing generality, let $U_{m}(x)=\left(x^{p / p}\right), 0<p<1$. Suppose that $V(t, x ; n)=e^{\beta_{0}(T-t)} U_{m}(x)$, where $\beta_{0}$ is a constant. We have

$$
\begin{aligned}
\beta_{0} V(t, x ; n)= & \left(r x+b_{1, t}^{n *}\left(\mu_{1}+n\right)+b_{2, t}^{n *} \mu_{2}\right) V_{x}(t, x ; n) \\
& +\frac{1}{2}\left(b_{1, t}^{n * 2} \sigma_{1}^{2}+b_{2, t}^{n * 2} \sigma_{2}^{2}+2 \rho b_{1, t}^{n *} \sigma_{1} b_{2, t}^{n *} \sigma_{2}\right) \\
& \cdot V_{x x}(t, x ; n),
\end{aligned}
$$

where $\left(b_{1, t}^{n *}, b_{2, t}^{n *}\right)$ is the optimal investment strategy. By some simple calculations, we can get that

$$
\beta_{0}=\beta_{0}(n)=A p\left(\frac{\left(\mu_{1}+n\right)^{2}}{2 \sigma_{1}^{2}}+\frac{\mu_{2}^{2}}{2 \sigma_{2}^{2}}-\frac{\rho\left(\mu_{1}+n\right) \mu_{2}}{\sigma_{1} \sigma_{2}}\right)+r p,
$$

where $A=\left(1 /\left((1-p)\left(1-\rho^{2}\right)\right)\right)$. We can also get the optimal investment strategy and the value function:

$$
\begin{aligned}
b_{1, t}^{n *} & =\frac{X^{*}(t ; n)\left(\left(\mu_{1}+n\right) \sigma_{2}-\rho \mu_{2} \sigma_{1}\right)}{\sigma_{1}^{2} \sigma_{2}\left(1-\rho^{2}\right)(1-p)}, \\
b_{2, t}^{n *} & =\frac{X^{*}(t ; n)\left(\mu_{2} \sigma_{1}-\rho\left(\mu_{1}+n\right) \sigma_{2}\right)}{\sigma_{1} \sigma_{2}^{2}\left(1-\rho^{2}\right)(1-p)}, \\
V(t, x ; n) & =\frac{e^{\beta_{0}(n)(T-t)} x^{p}}{p}
\end{aligned}
$$

where $X^{*}(t ; n)$ is the return of the fund under the optimal investment strategy.

3.2. The Optimal Effort Level of the Manager. Since on the one hand, the effort made by the manager brings a better performance of market 1 , and on the other hand, it produces a cost. Clearly, the net benefit of the manager is determined by the effort level. Since when $n=0$, the marginal utility of the effort is greater than zero, and the marginal cost of the effort is equal to zero; we know that at the beginning, the net benefit increases as the effort level increases. As time goes by, the marginal utility decreases and the marginal cost increases. When the marginal utility equals the marginal cost, the net benefit gets its maximum. Denoting this point by $n^{*}$, we have

$$
\left.\frac{\partial V(t, x ; n)}{\partial n}\right|_{n=n^{*}}=\left.\frac{\partial E[C(n)]}{\partial n}\right|_{n=n^{*}}
$$

Since the portion invested in market 1 is $b_{1, t}^{n *}$, we have

$$
R_{1}^{n}(t)=b_{1, t}^{n *}
$$

Then,

$$
E\left[R_{1}^{n}(t)\right]=E\left[b_{1, t}^{n *}\right]=\frac{\left(\mu_{1}+n\right) \sigma_{2}-\rho \mu_{2} \sigma_{1}}{\sigma_{1}^{2} \sigma_{2}\left(1-\rho^{2}\right)(1-p)} E\left[X^{*}(t ; n)\right] .
$$

Clearly, $E\left[R_{1}^{n}(t)\right]$ is finite; then, we can exchange the integration order of $E[C(n)]$ and obtain 


$$
\begin{aligned}
E[C(n)] & =e^{r T} \frac{\theta n^{2}}{2} \int_{0}^{T} e^{-r t} E\left[R_{1}^{n}(t)\right] \mathrm{d} t \\
& =\frac{\theta n^{2}}{2} \frac{\left(\mu_{1}+n\right) \sigma_{2}-\rho \mu_{2} \sigma_{1}}{\sigma_{1}^{2} \sigma_{2}\left(1-\rho^{2}\right)(1-p)} \frac{e^{(B(n)+r) T}-e^{r T}}{B(n)} x
\end{aligned}
$$

where $B(n)=\left(\left(\left(\mu_{1}+n\right)^{2}\right) /\left(\sigma_{1}^{2}(1-p)\right)\right)+\left(\mu_{2}^{2} /\left(\sigma_{2}^{2}(1-p)\right)\right)$.

In the following, we focus on the effects of parameters (such as the risk-free rate and the diffusion rate) on the optimal effort level. Since when $\rho=0, \mu_{1}=$ $\mu_{2}=\mu$, and $n \sigma_{1}=\sigma_{2}=\sigma$, the two markets have the same performance without the effect of the effort made by the fund manager, and we can focus on the effect of the manager's effort. In this case, according to (14), (15), and (18), we can get that the optimal effort level $n^{*}$ satisfies

$$
\begin{aligned}
\beta_{0}^{\prime}\left(n^{*}\right) \frac{e^{\beta_{0}\left(n^{*}\right)(T-t)} x^{p}}{p}= & \theta n^{*} \frac{\left(\mu+n^{*}\right)}{\sigma^{2}(1-p)} \frac{e^{\left(B\left(n^{*}\right)+r\right) T}-e^{r T}}{B\left(n^{*}\right)} x \\
& +\frac{\theta\left(n^{*}\right)^{2}}{2 \sigma^{2}(1-p)} \frac{e^{\left(B\left(n^{*}\right)+r\right) T}-e^{r T}}{B\left(n^{*}\right)} x \\
& +\frac{\theta\left(n^{*}\right)^{2}}{2} \frac{\left(\mu+n^{*}\right)}{\sigma^{2}(1-p)} \\
& \cdot \frac{e^{\left(B\left(n^{*}\right)+r\right) T} B^{\prime}\left(n^{*}\right)\left(B\left(n^{*}\right) T-1\right) x}{B\left(n^{*}\right)^{2}} .
\end{aligned}
$$

Clearly, (19) can define function $n^{*}$ which depends on the parameters of the financial market. In order to analyze the effects of parameters on the optimal effort level, we use $R$ software to get the graphs of the function for each parameter with other parameters fixed. The results are presented in graphs 1-6 in Figures 1-6.

\section{The Problem with Agency Conflicts}

In this section, we follow the steps mentioned in Section 2 to get the optimal strategies and the value functions of both sides. For simplicity, we consider the problem under the situation in which $w(\cdot)$ is a power function. That is, $w(x)=k x^{q}, k>0, q>0$.

4.1. The Optimal Nash Equilibrium Strategy. As mentioned above, first, let us fix the fund family's strategy and the fund manager's effort level. That is, $k, q$, and $n$ are fixed. Then, the compensation of the fund manager with policy $\pi=\left(b_{1, t}^{\pi}, b_{2, t}^{\pi}, n\right)$ is

$$
J_{m}^{\pi}(t, x ; n)=E\left[\frac{\left(k X^{\pi}(T ; n)^{q}\right)^{p}}{p} \mid X^{\pi}(0 ; n)=x\right] .
$$

Since this optimization problem is similar with the one solved in Section 3.1, with the same method, we have that the optimal investment strategies are

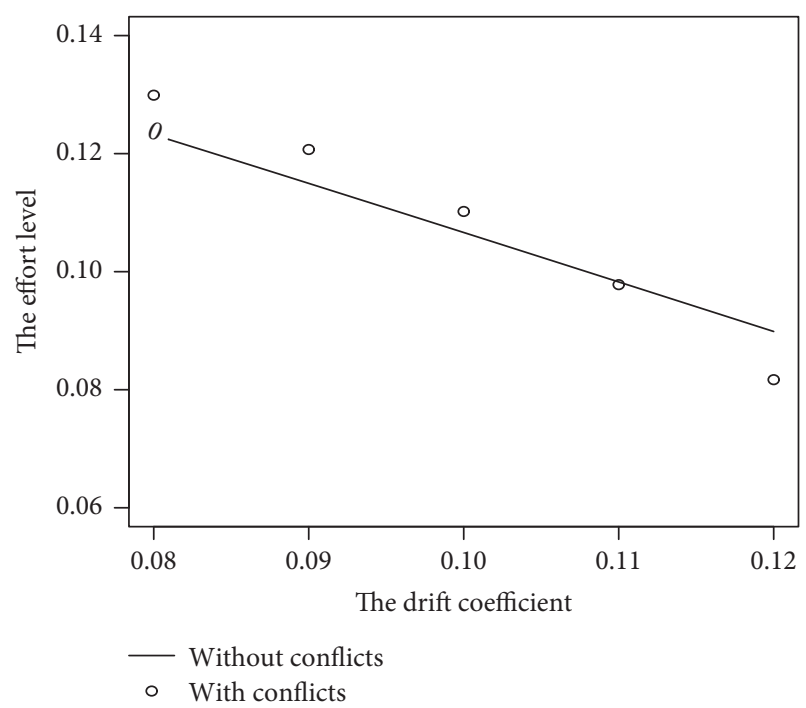

Figure 1: The effect of the drift coefficient on the optimal effort level

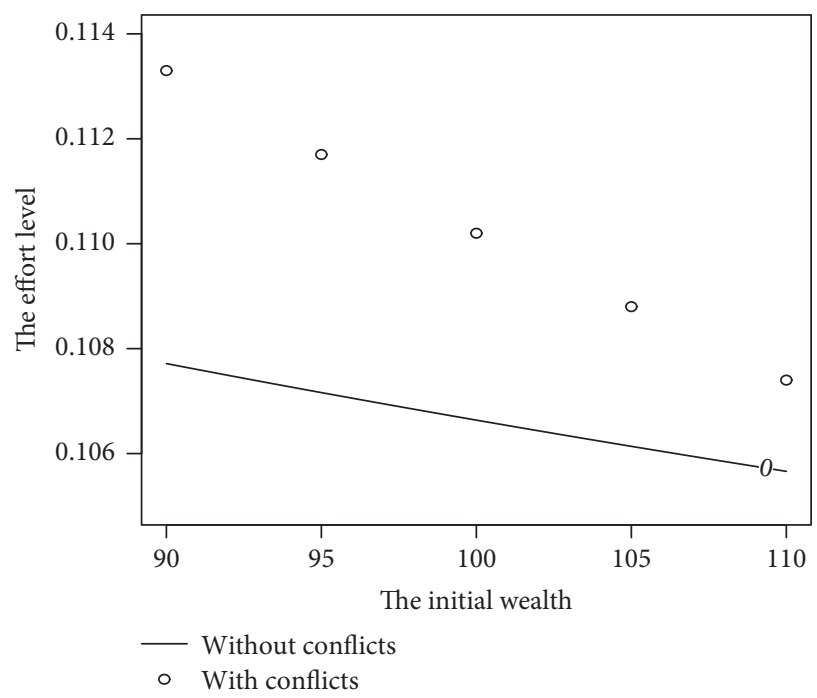

FIgURE 2: The effect of the initial wealth on the optimal effort level.

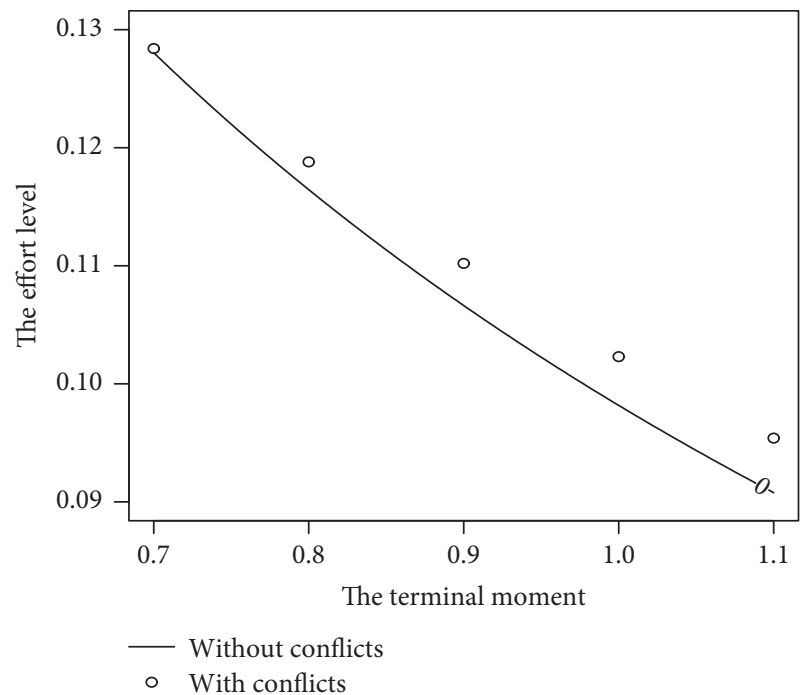

FIGURE 3: The effect of the terminal moment on the optimal effort level. 


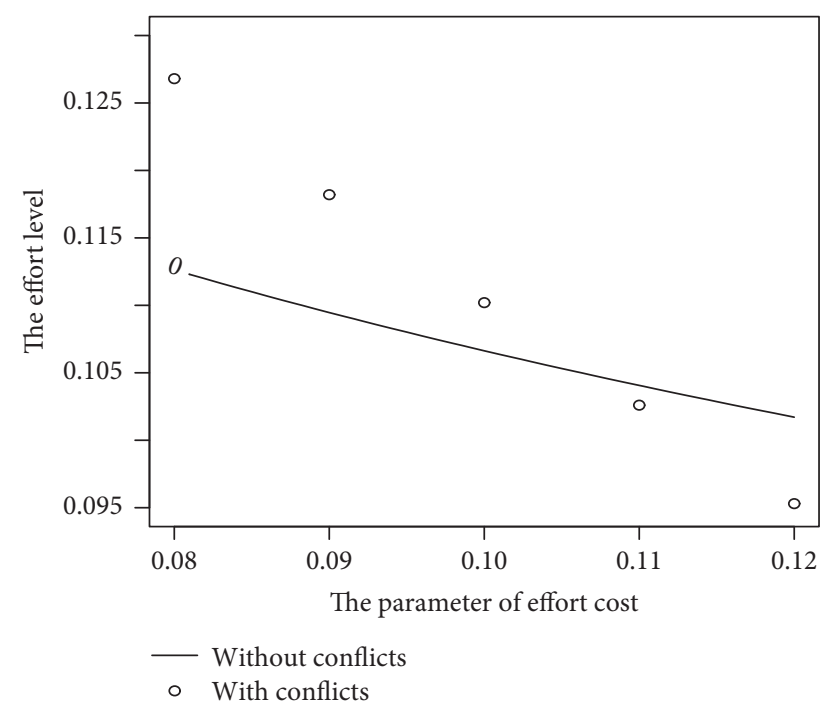

Figure 4: The effect of the effort cost on the optimal effort level.

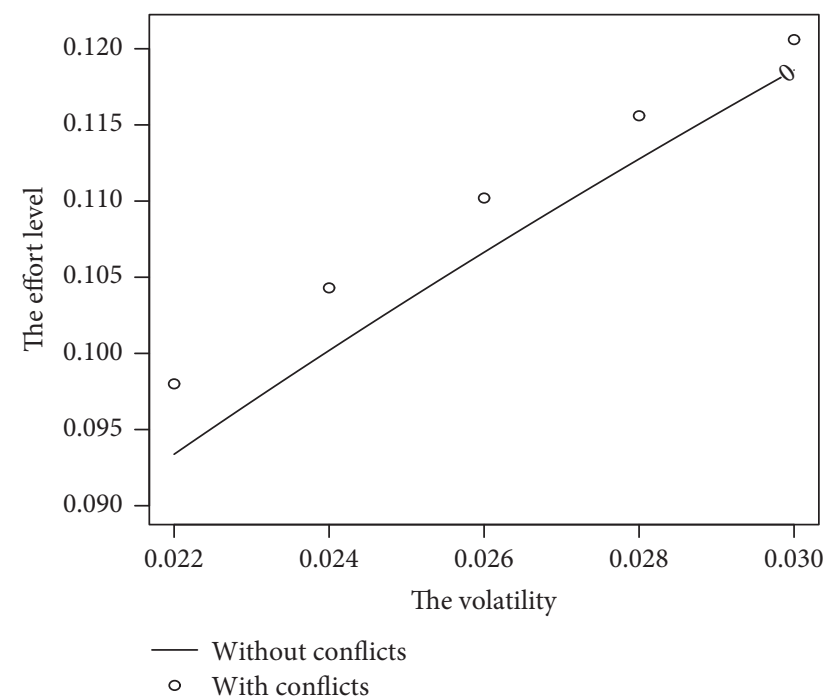

Figure 5: The effect of the volatility on the optimal effort level.

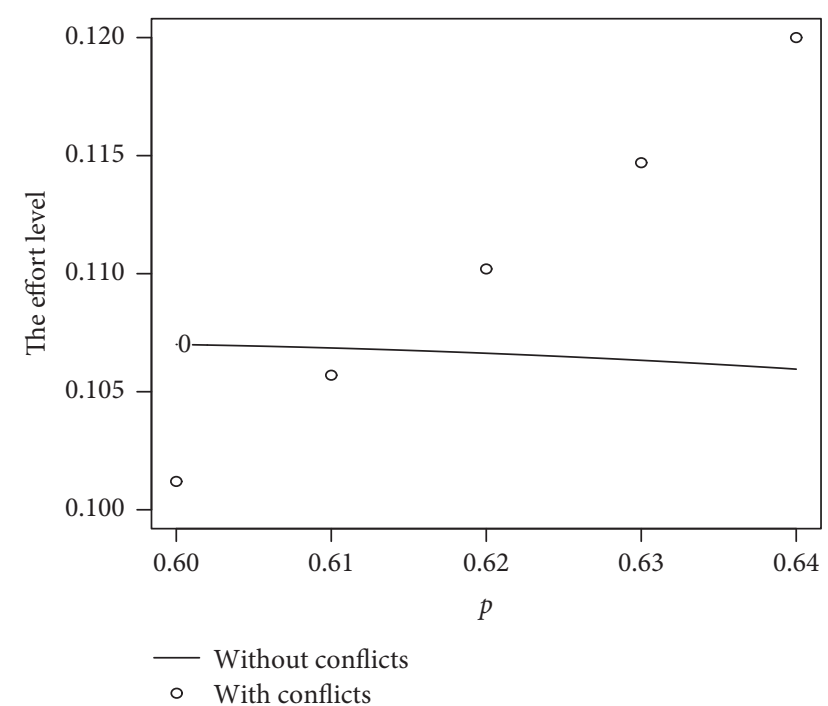

FIgURE 6: The effect of the risk aversion factor on the optimal effort level.

$$
\begin{aligned}
& b_{1, t}^{* k, q, n}=\frac{x\left(\left(\mu_{1}+n\right) \sigma_{2}-\rho \mu_{2} \sigma_{1}\right)}{\sigma_{1}^{2} \sigma_{2}\left(1-\rho^{2}\right)(1-q p)}, \\
& b_{2, t}^{* k, q, n}=\frac{x\left(\mu_{2} \sigma_{1}-\rho\left(\mu_{1}+n\right) \sigma_{2}\right)}{\sigma_{1}^{2} \sigma_{2}^{2}\left(1-\rho^{2}\right)(1-q p)},
\end{aligned}
$$

and the value function is

$$
V_{m}(t, x ; n)=\sup _{\pi \in \Pi} J_{m}^{\pi}(t, x ; n)=e^{\beta(n)(T-t)} \frac{\left(k x^{q}\right)^{p}}{p},
$$

where

$$
\beta(n)=A p q\left(\frac{\left(\mu_{1}+n\right)^{2}}{2 \sigma_{1}^{2}}+\frac{\mu_{2}^{2}}{2 \sigma_{2}^{2}}-\frac{\rho\left(\mu_{1}+n\right) \mu_{2}}{\sigma_{1} \sigma_{2}}\right)+r p q .
$$

Clearly, fixing $k$ and $q$, the optimal effort level $n^{*}$ satisfies the following equation:

$$
\left.\frac{\partial V_{m}(t, x ; n)}{\partial n}\right|_{n=n^{*}}=\left.\frac{\partial E[C(n)]}{\partial n}\right|_{n=n^{*}}
$$

It is shown from the above analysis that $n^{*}$ is a function of $k$ and $q$, and we denote it by $n^{*}(k, q)$.

Let us suppose that the two parts are all rational, and they will choose their strategy considering the opposite side. Then, if the fund family choose the income policy $k$ and $q$, he will confer that the manager will choose the optimal investment strategy

$$
\begin{aligned}
& b_{1, t}^{* k, q}=b_{1, t}^{* k, q, n^{*}(k, q)}, \\
& b_{2, t}^{* k, q}=b_{2, t}^{* k, q, n^{*}(k, q)},
\end{aligned}
$$

and the optimal effort level $n^{*}(k, q)$. Under this strategy, the benefit of the portfolio is

$$
\begin{aligned}
\mathrm{d} X^{* k, q}(t)= & \left(X^{* k, q}(t) r+b_{1, t}^{* k, q}\left(\mu_{1}+n^{*}(k, q)\right)+b_{2, t}^{* k, q} \mu_{2}\right) \mathrm{d} t \\
& +\sigma^{* k, q} \mathrm{~d} W(t),
\end{aligned}
$$

where $\quad \sigma^{* k, q}=\sqrt{\left(b_{1, t}^{* k, q}\right)^{2} \sigma_{1}^{2}+\left(b_{2, t}^{* k, q}\right)^{2} \sigma_{2}^{2}+2 \rho b_{1, t}^{* k, q} b_{2, t}^{* k, q} \sigma_{1} \sigma_{2}}$. The fund family's terminal value will be

$$
J_{f}^{k, q}(x)=E\left[X^{* k, q}(T)-k\left(X^{* k, q}(T)\right)^{q}\right] .
$$

Denote the value function by

$$
V_{f}(x)=\sup _{k>0, q>0} J_{f}^{k, q}(x) .
$$

4.2. The Effects of Parameters on the Optimal Effort Level and the Compensation Strategy. In this section, we will analyze the effect of parameters on the optimal strategies. Similar to the analysis in Section 3, let us still consider the case when $\rho=0, \mu_{1}=\mu_{2}=\mu$, and $\sigma_{1}=\sigma_{2}=\sigma$. Referring to (21), (22), and (27), we have 


$$
\begin{aligned}
b_{1, t}^{* k, q} & =\frac{X^{* k, q}(t)(\mu+n)}{\sigma^{2}(1-p q)} \\
b_{2, t}^{* k, q} & =\frac{X^{* k, q}(t) \mu}{\sigma^{2}(1-p q)} \\
\mathrm{d} X^{* k, q}(t) & =X^{* k, q}(t)\left[\left(r+\frac{\mu^{2}+(\mu+n)^{2}}{\sigma^{2}(1-p q)}\right) \mathrm{d} t+\sigma^{* k, q}\right] \mathrm{d} W(t)
\end{aligned}
$$

$d<X^{* k, q}>(t)=\left(\sigma^{* k, q}\right)^{2} \mathrm{~d} t$

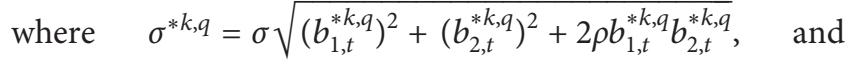
$n, k$, and $q$ satisfy (23).

Using Ito's formula, we can obtain that

$$
\begin{aligned}
\mathrm{d} X^{* k, q}(t)^{q}= & q X^{* k, q}(t)^{q-1} \mathrm{~d} X^{* k, q}(t) \\
& +\frac{q(q-1)}{2} X^{* k, q}(t)^{q-2} \mathrm{~d}\left\langle X^{* k, q}\right\rangle(t) .
\end{aligned}
$$

Combining with (30)-(33), we can obtain

$$
\mathrm{d} X^{* k, q}(t)^{q}=X^{* k, q}(t)^{q}\left\{\left[\left(r+\frac{(\mu+n)^{2}+\mu^{2}}{(1-q p) \sigma^{2}}\right) q+\frac{q(q-1)\left((\mu+n)^{2}+\mu^{2}\right)}{2 \sigma^{2}(1-q p)^{2}}\right] \mathrm{d} t+q \sigma^{* k, q} \mathrm{~d} W(t)\right\} .
$$

By some simple calculations, we can obtain that

$$
\begin{aligned}
& E\left[X^{* k, q}(T)^{q} \mid X^{* k, q}(0)=x\right]=\exp \left\{\left\{\left[r+\frac{\left.(\mu+n)^{2}+\mu^{2}\right]}{(1-q p) \sigma^{2}}\right] q+\frac{q(q-1)\left[(\mu+n)^{2}+\mu^{2}\right]}{2(1-q p)^{2} \sigma^{2}}\right\} T\right\} x^{q}, \\
& E\left[X^{* k, q}(T) \mid X^{* k, q}(0)=x\right]=\exp \left\{\left[r+\frac{(\mu+n)^{2}+\mu^{2}}{(1-q p) \sigma^{2}}\right] T\right\} x .
\end{aligned}
$$

Then, we have

$$
E\left[X^{* k, q}(T)-k\left(X^{* k, q}(T)\right)^{q}\right]=\exp \left\{\left[r+B_{0}(n)\right] T\right\} x-k \exp \left\{\left\{\left[r+B_{0}(n)\right] q+\frac{q(q-1) B_{0}(n)}{2(1-q p)}\right\} T\right\} x^{q}
$$

where $B_{0}(n)=\left(\left((\mu+n)^{2}+\mu^{2}\right) /\left((1-q p) \sigma^{2}\right)\right)$.

We want to find the optimal $k$ and $q$ to maximize (37) under the constraint (23), and $k>0$ and $q>0$. This is an optimization problem with constraints. This problem seems impossible to be solved explicitly. However, we can easily obtain the numerical solutions by using function donlp2 in software $R$.

By using $R$ software, the numerical results are illustrated in the following tables.

Table 1 shows that the fund manager's compensation and the effort level all decrease as the drift coefficient increases. Theoretically speaking, according to (23), both the cost of the fund manager's effort and the expected utility of the fund manager's compensation increase with the increase in drift coefficient $\mu$. Furthermore, the effort cost increases at a greater rate than the expected utility of compensation. So, the manager's optimal effort level decreases. This is consistent with the results in Table 1.

The optimal compensation strategy can be affected by the following two aspects:
(1) The drop of the optimal effort level can be inferred by the fund family which leads to a lower compensation

(2) The total benefit increases with the increase in drift coefficient which leads to a higher compensation

According to Table 1, we can see that the drop of the optimal effort level has a greater impact on the optimal compensation.

Table 2 reports that the fund manager's compensation increases as the initial wealth increases. The fund manager's effort level decreases as the initial wealth increases. Clearly, according to (23), both the cost of the fund manager's effort and the expected utility of the fund manager's compensation increase as the initial capital increases. Furthermore, the effort cost increases at a greater rate than the expected utility of compensation. In this situation, the manager's optimal effort level decreases. This is consistent with the results in Table 1. 
TABle 1: The effect of the drift coefficient on the optimal compensation and the optimal effort level.

\begin{tabular}{lcccc}
\hline$\mu$ & $k$ & $q$ & Wage & $n$ \\
\hline 0.08 & 1.8102 & 0.8812 & 104.7603 & 0.1299 \\
0.09 & 1.6567 & 0.8913 & 100.4070 & 0.1207 \\
0.10 & 1.4107 & 0.9061 & 91.5460 & 0.1102 \\
0.11 & 1.0535 & 0.9290 & 75.9769 & 0.0978 \\
0.12 & 1.1384 & 0.7488 & 35.6902 & 0.0817 \\
\hline
\end{tabular}

TABLe 2: The effect of the initial wealth on the optimal compensation and the optimal effort level.

\begin{tabular}{lcccc}
\hline$x$ & $k$ & $q$ & Compensation & $n$ \\
\hline 90 & 1.5803 & 0.8976 & 89.7285 & 0.1133 \\
95 & 1.4921 & 0.9019 & 90.6894 & 0.1117 \\
100 & 1.4107 & 0.9061 & 91.5460 & 0.1102 \\
105 & 1.3355 & 0.9101 & 92.3023 & 0.1088 \\
110 & 1.2657 & 0.9141 & 92.9645 & 0.1074 \\
\hline
\end{tabular}

For the optimal compensation strategy, on the one hand, the drop of the optimal effort level can be inferred by the fund family which leads to a lower compensation. On the other hand, the total benefit increases as the initial capital increases. This leads to a higher compensation. According to Table 2, we can see that the increase of the total benefit has a greater impact on the optimal compensation.

As a matter of fact, with the increase of the initial capital, the stability of return on assets is more important to the fund manager than the growth of return on assets. In this situation, the fund manager tends to invest more in risk-free assets and decrease the level of the effort. Considering the following two points:

(1) The decrease of the optimal effort level is due to risk aversion

(2) The increase of the initial capital increases the cost of the fund manager

The fund family will still increase the fund manager's compensation appropriately. This phenomenon can be explained perfectly by the results in Table 2 .

The results illustrated in Tables 3-5 can be explained similarly as the one mentioned above.

Table 6 illustrates that the compensation and the effort level of the fund manager all increase along with the decrease of the fund manager's risk aversion level. Clearly, the expected utility of the fund manager's compensation increases as the risk-averse level decreases. In this situation, the manager's optimal effort level increases.

For the optimal compensation policy, on the one hand, the increase of the effort level will raise the fund manager's compensation. On the other hand, the fund manager is more easily satisfied which can be inferred by the fund family. This leads to a lower compensation. According to Table 6, we can see that the increase of the effort level has a greater impact on the optimal compensation.

As a matter of fact, the fund manager with the lower riskaverse level tends to make a greater effort to get a higher Sharp ratio. The fund family can accurately identify the
TABLE 3: The effect of the terminal time on the optimal compensation and the optimal effort level.

\begin{tabular}{lcccc}
\hline$T$ & $k$ & $q$ & Compensation & $n$ \\
\hline 0.7 & 1.1975 & 0.9136 & 80.4269 & 0.1284 \\
0.8 & 1.3170 & 0.9088 & 86.5458 & 0.1188 \\
0.9 & 1.4107 & 0.9061 & 91.5460 & 0.1102 \\
1.0 & 1.4555 & 0.9060 & 94.4298 & 0.1023 \\
1.1 & 1.5044 & 0.9058 & 97.4911 & 0.0954 \\
\hline
\end{tabular}

TABLE 4: The effect of the effort cost on the optimal compensation and the optimal effort level.

\begin{tabular}{lcccc}
\hline$\theta$ & $k$ & $q$ & Compensation & $n$ \\
\hline 0.08 & 2.6906 & 0.8626 & 142.9222 & 0.1268 \\
0.09 & 1.9391 & 0.8845 & 113.9246 & 0.1182 \\
0.10 & 1.4107 & 0.9061 & 91.5460 & 0.1102 \\
0.11 & 1.0271 & 0.9278 & 73.6665 & 0.1026 \\
0.12 & 0.7468 & 0.9497 & 59.2311 & 0.0953 \\
\hline
\end{tabular}

TABLE 5: The effect of the fluctuation coefficient on the optimal compensation and the optimal effort level.

\begin{tabular}{lcccc}
\hline$\sigma^{2}$ & $k$ & $q$ & Compensation & $n$ \\
\hline 0.022 & 1.5008 & 0.9052 & 96.9997 & 0.0980 \\
0.024 & 1.4475 & 0.9059 & 93.8495 & 0.1043 \\
0.026 & 1.4107 & 0.9061 & 91.5461 & 0.1102 \\
0.028 & 1.3528 & 0.9077 & 88.4240 & 0.1156 \\
0.030 & 1.2935 & 0.9097 & 85.3381 & 0.1206 \\
\hline
\end{tabular}

TABle 6: The effect of the risk aversion factor on the optimal compensation and the optimal effort level.

\begin{tabular}{lcccc}
\hline$p$ & $k$ & $q$ & Compensation & $n$ \\
\hline 0.60 & 0.7942 & 0.9432 & 60.9005 & 0.1012 \\
0.61 & 1.0608 & 0.9238 & 74.6961 & 0.10 \\
0.62 & 1.4107 & 0.9061 & 91.5460 & 0.1102 \\
0.63 & 1.8409 & 0.8902 & 111.0353 & 0.1147 \\
0.64 & 2.4748 & 0.8727 & 137.7054 & 0.1200 \\
\hline
\end{tabular}

manager's risk preference and speculate that the manager's optimal effort level increases as the risk-averse level decreases and then properly increases the manager's compensation to reward him for the effort.

By using $R$ software, the graphs of the optimal effort level changing with parameters with and without agency conflicts are presented in Figures 1-6.

\section{Conclusion}

According to graphs $1-5$, we can see that the optimal effort levels have the same change tendency in the cases with and without agency conflicts. This implies that the manager flourishes if the fund family flourishes. However, the ascending (descending) speed is different because of the effect of agency conflicts. It is shown from graph 6 that the optimal effort levels have the opposite change tendency in two cases. In the case when there are no agency conflicts, the effort level decreases along with the decrease of the fund manager's risk 
aversion level. In fact, in this case, the fund manager is in the position of the fund family. A decrease of the fund manager's risk aversion level is equivalent to a decrease of the fund family's risk aversion level, which is a relative increase of the fund manager's risk aversion level in the case with agency conflicts. So, the two results in the two cases are consistent.

We can also suppose that the effort level will change with time. In this case, the corresponding HJB equation of the agent optimization problem does not have an explicit solution, which implies that the dynamic programming principle cannot be used any more. Since the martingale representation theorem is usually applied to give a representation of the agent's true continuation value (Sannikov [18], He [19] for example), we can deduce that this problem may also be solved by applying the martingale representation theorem. Anyone interested in this more complex problem can continue to do some research.

\section{Data Availability}

The conclusion of this paper is given in the form of an expression with respect to some parameters. No data were used to support this study. The data in the table are selected for the analysis of the influence of each parameter in the expression on the optimal effort level.

\section{Conflicts of Interest}

The authors declare that they have no conflicts of interest.

\section{Acknowledgments}

This work was partially supported by the National Natural Science Foundation of China (Grant no. 11901404).

\section{References}

[1] A. Almazan, K. C. Brown, M. Carlson, and D. A. Chapman, "Why constrain your mutual fund manager?" Journal of Financial Economics, vol. 73, no. 2, pp. 289-321, 2004.

[2] M. K. Brunnermeier and L. H. Pedersen, "Market liquidity and funding liquidity," Review of Financial Studies, vol. 22, no. 6, pp. 2201-2238, 2009.

[3] P. H. Dybvig, H. K. Farnsworth, and J. N. Carpenter, "Portfolio performance and agency," Review of Financial Studies, vol. 23, no. 1, pp. 1-23, 2010.

[4] S. Gervais, A. W. Lynch, and D. K. Musto, "Fund families as delegated monitors of money managers," Review of Financial Studies, vol. 18, no. 4, pp. 1139-1169, 2005.

[5] V. Guerrieri and P. Kondor, "Fund managers, career concerns, and asset price volatility," American Economic Review, vol. 102, no. 5, pp. 1986-2017, 2012.

[6] S. Ross, "The economic theory of agency: the principal's problem," American Economic Review, vol. 63, no. 2, pp. 134-139, 1973.

[7] J. A. Mirrlees, "The optimal structure of incentives and authority within an organization," The Bell Journal of Economics, vol. 7, no. 1, pp. 105-131, 1976.

[8] B. Holmstrom, "Moral hazard and observability," The Bell Journal of Economics, vol. 10, no. 1, pp. 74-91, 1979.

[9] P. Bolton and M. Dewatripont, Contract Theory, MIT Press, Cambridge, UK, 2005.
[10] B. Holmstrom and P. Milgrom, "Aggregation and linearity in the provision of intertemporal incentives," Econometrica, vol. 55, no. 2, pp. 303-328, 1987.

[11] H. Schättler and J. Sung, "The first-order approach to the continuous-time principal-agent problem with exponential utility," Journal of Economic Theory, vol. 61, no. 2, pp. 331-371, 1993.

[12] H. Schättler and J. Sung, "On optimal sharing rules in discrete-and continuous-time principal-agent problems with exponential utility," Journal of Economic Dynamics and Control, vol. 21, no. 2-3, pp. 551-574, 1997.

[13] H. Müller, "The first-best sharing rule in the continuous-time principal-agent problem with exponential utility," Journal of Economic Theory, vol. 79, no. 2, pp. 276-280, 1998.

[14] H. M. Müller, "Asymptotic efficiency in dynamic principalagent problems," Journal of Economic Theory, vol. 91, no. 2, pp. 292-301, 2000.

[15] J. Cvitanić, X. Wan, and J. Zhang, "Optimal compensation with hidden action and lump-sum payment in a continuoustime model," Applied Mathematics and Optimization, vol. 59, pp. 99-146, 2009.

[16] J. Cvitanić and J. Zhang, Contract Theory in Continuous Time Models, Springer-Verlag, Berlin, Germany, 2013.

[17] N. Williams, On Dynamic Principal-Agent Problems in Continuous Time, Working Paper, University of Wisconsin, Madison, WI, USA, 2009.

[18] Y. Sannikov, "A continuous-time version of the principalagent problem," Review of Economic Studies, vol. 75, no. 3, pp. 957-984, 2008.

[19] Z. He, "A model of dynamic compensation and capital structure," Journal of Financial Economics, vol. 100, no. 2, pp. 351-366, 2011.

[20] Z. He and W. Xiong, "Delegated asset management, investment mandates, and capital immobility," Journal of Financial Economics, vol. 107, no. 2, pp. 239-258, 2013.

[21] W. Fleming and H. Soner, Controlled Markov Processes and Viscosity Solutions, Springer-Verlag, New York, NY, USA, 1993. 